\title{
The Effect of Information Technology on Innovation Abilities: A Research on SMEs
}

\author{
Himmet Karadal (Aksaray University, Turkey) \\ Muhammet Saygın (Aksaray University, Turkey)
}

\begin{abstract}
The use of information technologies (IT) and increase of innovation activities within Small and Medium Sized Enterprises (SMEs) which can easily adapt to the dynamics and changes can contribute to the regional development process. Though some studies have been concerned about the effect of information technologies or innovation on management performance, it can be easily seen that there has been very little empirical work for Small and Medium Sized Enterprises. Accordingly, the purpose of this study is to analyze the effects of information technologies within Small and Medium Sized Enterprises on innovation (product or process innovation) and management performance. In this study data will be collected through SMEs in Aksaray province and in this way study will deal with the relationship between information technology, innovation and management performance. Data for the research will be collected through survey system. The questions of the survey will be created by using the theoretical and applied literature (validity and reliability tested in various contexts) including information technologies, innovation and performance. Unlike some of the questions taken from previous studies, the new ones will be developed in terms of literature review, recommendations of academic staffs and business managers. The analysis of collected data will be carried out through SPSS package program and by using the techniques of some tests like single sample - t- test and ANOVA test.
\end{abstract}

JEL Codes: O31, O33

\section{Introduction}

The concept of IT has improved its importance in recent years and become indispensable for operational areas as well as management science. IT is affecting not only academic committees, businesses, local authorities and international institutions but also individual users in every aspects of life. The use of information technologies and increase of innovation activities within Small and Medium Sized Enterprises which can easily adapt to the dynamics and changes can contribute to the regional development process.

In the world of globalization, information technologies playing the key role of change and actuality are also undertaking the basis of innovation. Organizations dealing with the IT management should tend to innovation efforts and need to work on different models and methods in order to differentiate themselves against global competition. In our globalized world where the growth and development no longer depend on individual factors, the rapid increase of technological improvement reveals the importance of innovation and informatics. The concept of innovation which is both one of the most critical factors of both micro and macro - economic growth and development and providing a competitive advantage has a connection with information systems and its effect in management level occur as a phenomenon emerging in all areas. The use of information technologies and increase of innovation activities within Small and Medium Sized Enterprises should be analyzed. Though some studies have been concerned about the effect of information technologies or innovation on management performance, it can be easily seen that there has been very little empirical work for Small and Medium Sized Enterprises.

In this study, use of information system levels within the enterprises located in Aksaray was determined, their innovation capabilities were questioned and the relationship between information and innovation through the management based inferences were indicated. Unlike some of the questions taken from previous studies, the new ones were developed in terms of literature review, recommendations of academic staffs and business managers. The analysis of collected data was carried out through SPSS package program and by using the techniques of some tests like single sample $-\mathrm{t}$ - test and ANOVA test.

\section{Theoretical Framework}

Prior to addressing the information technologies, it might be important to mention about the different aspects of data, information, knowledge and wisdom terms. These four concepts of data, information, knowledge and wisdom are fundamental in terms of information technologies and meaning differences among these terms should be identified. Attempts to define these concepts are numerous and produce slightly different results, depending on which discipline is looking at them. Data are defined by dictionaries as factual information used as a basis for reasoning, discussion, or calculation; information as the communication or reception of knowledge; knowledge as the condition of knowing something gained through experience or the condition of apprehending truth or fact through reasoning (Bouthillier and Kathleen, 2002). For Meadow, et al. (2000), data refer to a string 
of elementary symbols, such as digits or letters. As it is pointed out, information "has no universally accepted meaning, but generally it carries the connotation of evaluated, validated or useful data". Knowledge, on the other hand, involves "a higher degree of certainty or validity than information" and "has the characteristic of information shared and agreed upon within a community. To conclude the meanings of these three terms, the term data refers to qualitative or quantitative attributes of a variable or set of variables. Data which are the plural form of datum are typically the results of measurements and can be the basis of graphs, images, or observations of a set of variables. Data are often viewed as the lowest level of abstraction from which information and then knowledge are derived. (URL-1). Information meets the definition for knowledge by description and is differentiated from data in that it is useful. Information is inferred from data in the process of answering interrogative questions (Rowley and Hartley, 2006). American educator Bob Boiko defines information only as "matter-of-fact" (Wallace, 2007). Knowledge is a fluid mix of framed experience, values, contextual information, expert insight and grounded intuition that provides an environment and framework for evaluating and incorporating new experiences and information. It originates and is applied in the minds of knowers. In organizations it often becomes embedded not only in documents and repositories but also in organizational routines, processes, practices and norms (Davenport, 1998). Lastly, wisdom which is commonly included as a level in data, information, knowledge, has a limited reference to wisdom. Wisdom is the ability to increase effectiveness. Wisdom adds value, which requires the mental function that we call judgment. The ethical and aesthetic values that this implies are inherent to the actor and are unique and personal (Rowley and Hartley, 2006).

The concept of IT is defined as an information system which is collecting the necessary information from various sources; processing, storing and reporting the data in order that manager can decide (Tekin, 2003). Information technology has a dramatic impact on organizational structure and re-design of the individual's position. The presence of information and communication technologies in organizations has expanded significantly to a point where there is no organization that can function without these tools. Coupled with this expansion is an increasing recognition of information and knowledge as indispensable and valuable assets in every organization (Parsons 2004). The success of every organization depends largely on how well it uses information technology to manage its information and knowledge resources (Cascio 2001).

In this study, we analyzed the relationship between IT use and innovation within the businesses; in this regard innovation concept should be identified. In recent years, the word innovation became one of the most popular concepts in daily life. It can be seen everywhere. However, this widespread usage of innovation lets us indentify the meaning. There are many innovation meanings in the literature. According to academic and business literature, innovation means to make an idea technically and commercially marketable and accessible to larger production in order to continue with sales (Casper and Waarden, 2003). Innovation is a pervasive attitude, a feeling, an emotional state, an ongoing commitment to newness. It is a set of values that represents a belief in seeing beyond the present making that vision a reality (Kuczmarzki, 2003). There are several perspectives for explaining innovation types. For example Tidd, Bessant \& Pavitt (2005) base their classification of innovation on change. They focus on four broad categories, these are:

- Product innovation - Changes in the things which an organization offers;

- Process innovation - Changes in the ways in which the products/services are created and delivered;

- Position innovation - Changes in the context in which the products/services are introduced

- Paradigm innovation - Changes in the underlying mental models which frame what the organization does

\section{Findings}

This research was conducted in order to be a framework for the small and medium sized enterprises in Aksaray province. In this study, one faculty member at University of Aksaray and one specialist from the same university were involved. A variety of methods were used to collect the data: (1) semi-structured interviews with the managers; (2) in-dept questionnaires completed by the managers and the top management team of the businesses and (3) publicly available internet connections (eg: annual reports, web sources and web sites). The reason why these three methods were used actually indicates the purpose of this study. That is, the use of first method makes the study more realistic. When the managers of these businesses were interviewed before the questionnaires' application, researchers more easily gained the access to have answers for the questions in data collection tool. Thus, interviews with the managers let us collect the data more accurately and more easily. One more benefit of this multi-method approach occurred as the avoidance of method variance, as different groups of the variables were determined from the use of this three data collection method (Campbell \& Fiske, 1959). Besides that, the data collection tool was designed in terms of the literature analysis and many questions were taken and some of the questions were designed from the study of Bülbül (2003) and Güleş (1996). 


\begin{tabular}{|c|c|c|c|}
\hline Level of IT Use & Mean & (n) & St. Dev. \\
\hline IT Systems - 5 Years Ago & 35,2692 & 104 & 13,16234 \\
\hline IT Systems - Actual & 52,1058 & 104 & 21,19164 \\
\hline
\end{tabular}

Table 1: The Use of Information Technologies in SMEs

The table 1 indicates that there is a meaningful difference between the past and actual use levels. That is, 104 businesses attended to the research have an increase in terms of the usage levels of information technologies in their businesses. This implies that businesses in Aksaray province try to follow the new technologies and adapt these technologies to their production and management methods. It can also be understood as an improvement for the future plans of the city itself.

\begin{tabular}{|c|c|c|c|c|}
\hline Difference Indicator & Mean & St. Dev. & Df & $\mathrm{p}$ \\
\hline ITbefore - ITnow & $-16,83654$ & 15,11452 & 103 &, 000 \\
\hline
\end{tabular}

Table 2: Increase in the level of IT use in SMEs. Note: (i): $t: 11,360 ;$ (ii): $p:<001$

The indicated results of the increases of the use of information technologies is shown in the table 2 and this table indicates that the increase level occurs as $-16,83654$ so we can conclude that there is a meaningful increase level and businesses are really interested in changes and developments. That is there can be a potential both for the businesses themselves and the Aksaray province because it should be believed that the more potential within the city and its businesses, the more easily the improvements are carried out.

\begin{tabular}{|c|c|c|c|c|c|}
\hline Effects of IT on Innovation Concepts & (n) & Min. & Max. & Mean & St. Dev. \\
\hline IT has an effect on the new production \\
ideas & 104 & 1 & 5 & 3,14 & 1,234 \\
\hline $\begin{array}{c}\text { IT has an effect on the innovation of } \\
\text { production works }\end{array}$ & 104 & 1 & 5 & 2,32 & 1,457 \\
\hline $\begin{array}{c}\text { IT has an effect on the decrease of } \\
\text { development process of the new products }\end{array}$ & 104 & 1 & 5 & 2,46 & 1,350 \\
\hline $\begin{array}{c}\text { IT has an effect on the decrease of the } \\
\text { changes in product designs }\end{array}$ & 104 & 1 & 5 & 2,39 & 1,325 \\
\hline $\begin{array}{c}\text { IT has an effect on the convenience of the } \\
\text { new product for the customers }\end{array}$ & 104 & 1 & 5 & 3,11 & 1,481 \\
\hline
\end{tabular}

Table 3: The Effects of IT on Innovation. Note: (i): Scale: 1-don't agree ......5-definitely agree

In the data collection tool, businesses were asked to determine the effects of information technologies on innovation within their businesses and five variables were given to the managers. These variables were taken form the studies of Güleş (2003) and given results were taken from the unpublished master thesis of Saygın (2011). According to these data, businesses share the idea that information technologies have an effect especially on the new product ideas. Besides that the second most common answer for this question is that information technologies have an effect on the convenience of the new product for the customers. It shows us that businesses in Aksaray province choose the new product ideas more commonly as a reason for the information technologies' use.

\begin{tabular}{|c|c|c|c|c|c|}
\hline Innovation Abilities & $(\mathrm{n})$ & Mean & St. Dev. & $\mathrm{t}$ & $\mathrm{p}$ \\
\hline New products & 104 & 3,40 & 1,235 & 3,335 & $<.001$ \\
\hline New production methods & 104 & 2,74 & 1,435 & $-1,845$ & $<.005$ \\
\hline New organizational types & 104 & 2,23 & 1,443 & $-5,436$ & $<.001$ \\
\hline $\begin{array}{c}\text { New methods of procurement and } \\
\text { distribution }\end{array}$ & 104 & 2,31 & 1,455 & $-4,851$ & $<.001$ \\
\hline
\end{tabular}

Table 4: Innovation Abilities of the Businesses.

Note: (i) n=104; (ii) one sample t-test; (iii) Scale: 1- never done ......5-very highly done

The table indicates that businesses have different reasons for the innovation and these differences are given by the table 4. According to this, businesses prefer making innovations on new products. The variable occurs as the most preferred choice for innovation abilities. Besides that, new production methods are also chosen as a way of making innovation.

\section{Conclusion}

In this study, use of information system levels within the businesses located in Aksaray was determined and the levels were indicated in the study. First of all, the difference between past and the actual use levels were given. According to this, businesses in Aksaray province definitely increased their levels of IT use. That is when 
today's situation is compared with the five years ago, it can easily be seen that there is an effort to adapt at changes in the world. Secondly, innovation effects for the businesses are tried to be explained and it has been clearly seen that businesses share the opinion of that there is a definite effect of IT on the new product ideas. So, it can be concluded that businesses are trying to create new products to compete with the other businesses and for this aim they are using the information technologies. When the businesses asked for other important effects of IT, the second outstanding answer about this question occurs as convenience of the new products for the customers. To sum up, businesses use the information technologies in an active way and try to create new product ideas and make their productions convenient for their customers' needs. Thirdly, innovation abilities of the businesses are tried to be explained and the results of the data collection tool showed that businesses are mostly capable of new products. Most of the businesses have indicated that they are trying to create new products. When it is analyzed through the globalization term, this should make us hopeful about the future of the city and of course the country so that there is a great potential of production abilities in the city. In conclusion, collected data confirm that there is an increase for the levels of information technologies use within the businesses in Aksaray province and these businesses are trying to adapt these technologies to their innovation abilities.

In this regard, though there are a lot of benefits of IT use for the businesses, they want to take advantage of new production capabilities and among the many different ways for their innovations, the most outstanding one occurs as the choice of creating new products.

\section{References}

- Bouthillier, B. and Kathleen, S., 2002, Understanding Knowledge Management and Information Management: The Need for an Empirical Perspective, Information Research, Vol. 8 No: 1, Graduate School of Library and Information Studies McGill University Montreal, Canada.

- Casper, S. and Waarden, F., 2005. Innovation and institutions: a programmatic study, Cheltenham, UK.

- Cascio, WF 2001. Knowledge creation for practical solutions appropriate to a changing world of work, Journal of Industrial Technology, 27(AO): 14 - 16.

- Davenport, Thomas H.; Laurence Prusack (1998). Working Knowledge: How Organizations Manage What They Know. Boston: Harvard Business School Press. pp. 5. ISBN 0585056560.

- Kuczmarski, T.D., 2003. Why is innovation? Why aren't companies doing more of it?, Journal of Consumer Marketing, 20, 536-541.

- Meadow, C. T., Boyce, B.R. and Kraft, D.H.(2000) Text information retrieval systems, $2^{\text {nd }}$ ed. San Diego, CA: Academic Press.

- Parson, M. 2004. Effective knowledge management for law firms. Oxford: Oxford University Press.

- Rowley, Jennifer; Richard Hartley (2006). Organizing Knowledge: An Introduction to Managing Access to Information. Ashgate Publishing, Ltd. pp. 5-6. ISBN 9780754644316.

- Saygin, M., 2011, “An Analysis Of Relationships Between Use Of It Technologies And Innovation Abilities Within Businesses”, Unpublished MBA Thesis, Aksaray University, Institute of Social Sciences, Master of Business Administration, Aksaray, Turkey.

- $\quad$ Tekin, M., Güles, H.K., Ögüt, A., 2003. Değişim Çağında Teknoloji Yönetimi, Nobel Yayın

- Dağıtım, 2. Baskı, Ankara, s.139.

- Tidd, J., Bessant J., \& Pavitt, K. (2005). Managing Innovation - Integrating Technological, Market and Organizational Change (3rd Ed.). UK: John Wiley \&Sons.

- Wallace, Danny P. (2007). Knowledge Management: Historical and Cross-Disciplinary Themes. Libraries Unlimited. pp. 1-14. ISBN 9781591585022.

- URL-1, http://en.wikipedia.org/wiki/Data 